\title{
Implicações da pandemia da COVID-19 para o financiamento da educação básica
}

\section{Thiago Alves 1}

Nalú Farenzena ${ }^{2}$

Adriana A. Dragone Silveira ${ }^{3}$

José Marcelino de Rezende Pinto ${ }^{4}$

1 Universidade Federal de Goiás / Faculdade de Administração, Ciências Contábeis e Ciências Econômicas Programa de PósGraduação em Administração, Goiânia / GO - Brasil

2 Universidade Federal do Rio Grande do Sul / Faculdade de Educação, Programa de Pós-Graduação em Educação, Porto Alegre /

RS - Brasil

${ }^{3}$ Universidade Federal do Paraná / Departamento de Planejamento e Administração Escolar, Programa de Pós-Graduação em Educação, Curitiba / PR - Brasil

${ }^{4}$ Universidade de São Paulo / Faculdade de Filosofia, Ciencias e Letras de Ribeirão Preto, Programa de Pós-Graduação em Educação, Ribeirão Preto / São Paulo - Brasil

O objetivo do presente artigo é estimar impactos da queda da arrecadação tributária para o financiamento da educação básica em virtude dos efeitos econômicos adversos da pandemia da COVID-19. Para tanto, são analisados três cenários hipotéticos de queda da arrecadação e seus efeitos para as receitas da educação nos estados e municípios, por meio de um modelo de previsão que combinou dados de receitas de impostos com receitas vinculadas a educação e matrículas. No cenário mais otimista, a redução da receita líquida de impostos de $7 \%$ implicaria um decréscimo dos recursos para educação básica de $\mathrm{R} \$ 16,6$ bilhões por ano. A receita aluno-mês, que, em 2018 , foi de $\mathrm{R} \$ 460,00$ em média, poderia cair em proporções que variam entre $4,1 \%$ e $26,9 \%$, a depender do cenário de redução e do contexto de cada município. Diante da previsível diminuição de recursos, são propostas medidas urgentes para atenuar o aprofundamento das desigualdades na educação, as quais convergem para a transferência de recursos da União aos governos subnacionais. Finalmente ressalta-se o papel virtuoso do investimento na educação, dada a capilaridade desta e o seu caráter intensivo em pessoal.

Palavras-chave: COVID-19; financiamento da educação básica; desigualdades educacionais; políticas educacionais.

\section{Implicaciones de la pandemia de COVID-19 para la financiación de la educación básica}

El objetivo del artículo es estimar los impactos de la caída de la recaudación tributaria en el financiamiento de la educación básica frente a los efectos económicos adversos de la pandemia de COVID-19. Para ello, se analizan tres escenarios hipotéticos de caída de la recaudación y sus efectos sobre el presupuesto educativo y por alumno en los estados y municipios, por medio de una metodología que combinó datos de ingresos tributarios, recursos impositivos vinculados a la educación y matrículas. En el escenario más optimista, la reducción del 7\% de los ingresos tributarios líquidos implicaría una disminución de los recursos para la educación básica de R\$16,6 mil millones. Los recursos mensuales por alumno que en 2018 fueron de R \$460,00 en promedio, podrían caer de 4,1\% a 26,9\%, dependiendo del escenario de reducción. Frente a la previsible disminución de recursos, se proponen medidas urgentes para atenuar la profundización de las desigualdades en la educación, las cuales convergen en la transferencia de recursos federales a los gobiernos subnacionales. Finalmente se resalta el papel virtuoso de la inversión educativa en la economía, dada la capilaridad de la educación y su carácter intensivo en personal.

Palabras clave: COVID-19; financiamiento de la educación básica; desigualdades educativas; políticas educativas. 


\section{Implications of the COVID-19 pandemic on funding basic education}

This article aims to estimate the impact of lower tax revenues on the funding of basic education, in the context of the economic impact of the COVID-19 pandemic. Three hypothetical scenarios of lowering tax revenues are estimated and analyzed, along with their effects on the investment in education in the states and municipalities, per-pupil and overall, using a methodology that combines data on tax revenues, mandatory allocation in education, and enrollment numbers. In the most optimistic scenario, the reduction of $7 \%$ in the net tax revenues would lead to a decrease in investment in basic education of more than $\mathrm{R} \$ 16.6$ billion. The monthly per-pupil expenditure, which in 2018 was $\mathrm{R} \$ 460$ on average, could drop between $4.1 \%$ and $26.9 \%$ depending on which scenario is considered. This probable reduction in revenues requires urgent measures to attenuate the deepening of educational inequalities, converging to the transference of federal funds to sub-national governments. Finally, we highlight the economic virtue of investing in education, when considering the capillarity of education, and its character of intensive investment in personnel.

Keywords: COVID-19; school funding; educational inequalities; educational policies.

\section{INTRODUÇÃO}

A confirmação do primeiro caso de contaminação pelo novo coronavírus (COVID-19) no Brasil nos últimos dias de fevereiro colocou as autoridades em alerta e, gradativamente, regras para o distanciamento social foram sendo impostas a fim de mitigar o aumento no número de casos. A partir da segunda quinzena de março, em vários estados brasileiros, os estabelecimentos de ensino cessaram as atividades presenciais com base em normativas que impuseram restrição ao seu funcionamento. Teve início, ainda, a demissão de professores temporários, estagiários e funcionários de limpeza e alimentação contratados por empresas terceirizadas.

Neste contexto, destacam-se os impactos negativos da crise sobre os estudantes da rede pública, os quais dependem, majoritariamente, das escolas para exercerem seu direito à educação. Diferentemente das escolas privadas, a grande maioria dos alunos da rede pública não dispõe de condições adequadas (computadores, acesso à internet, espaço físico, mobiliário etc.) para a realização de atividades educacionais em casa. Pesa, ainda, sobre um número expressivo de crianças muito pobres o impacto do ponto de vista nutricional, pois, juntamente com as aulas, elas também perderam o acesso à alimentação escolar.

Embora os desafios para o processo pedagógico decorrentes da pandemia sejam imediatos e fundamentais, este artigo focaliza impactos da queda da arrecadação tributária para o financiamento das escolas públicas de educação básica. O pressuposto subjacente é de que a redução dos recursos para o setor pode aumentar consideravelmente as desigualdades nas condições de oferta de ensino, principalmente nas regiões e localidades mais pobres e com menor arrecadação tributária.

Uma das consequências imediatas da pandemia é a significativa redução das atividades econômicas, que tem efeitos negativos sobre a arrecadação tributária. Estudos do Banco Mundial (World Bank, 2020) estimam uma queda de 5\% do Produto Interno Bruto (PIB) no Brasil em 2020, e outros, a queda de $20 \%$ a 30\% na arrecadação do Imposto sobre Circulação de Mercadorias e Serviços (ICMS) de abril em comparação com a do mês de março (Watanabe, 2020). Assim, considerando que a principal fonte de financiamento das escolas públicas de educação básica é a vinculação de receitas líquidas de impostos (RLI), prevê-se que haja intensa perda de recursos para a educação, como já apontam estudos em países cujo sistema de financiamento educacional assemelha-se ao do Brasil (Baker \& Di Carlo, 2020). 
A educação pública no Brasil conta com recursos vinculados, os quais lhe garantem certa estabilidade. Contudo eles são insuficientes para oferecer um bom padrão de qualidade de ensino e para diminuir as desigualdades de condições de oferta de ensino ocasionadas pela disparidade de capacidade de gasto por aluno entre estados e municípios, como atestam estudos sobre o cumprimento das metas do Plano Nacional de Educação ([PNE], Lei n. 13.005/2014) para o decênio 2014-2024 (Instituto Nacional de Estudos e Pesquisas Educacionais Anísio Teixeira [INEP], 2018). O valor médio do gasto por aluno no Brasil corresponde a cerca de um terço da média dos países da Organização para a Cooperação e Desenvolvimento Econômico (OECD, 2019) e a menos da metade do valor praticado pelas escolas privadas frequentadas pelos estudantes da classe média.

$\mathrm{O}$ artigo apresenta um sucinto quadro da oferta e do financiamento educacional no Brasil, e estima cenários da arrecadação neste contexto de recessão econômica e seus efeitos para a receita educacional nos estados e municípios. Nas considerações finais, são sublinhadas medidas urgentes para atenuar o aprofundamento das desigualdades na educação.

\section{DESAFIOS DO FEDERALISMO EDUCACIONAL BRASILEIRO}

Com base no regime de colaboração entre União, estados e municípios estabelecido no art. 211 da Constituição Federal (CF, 1988), as ações do Estado na educação básica ocorrem por meio de uma complexa teia de relações intergovernamentais e de instituições com funções de gestão e regulamentação. De acordo com o Censo Escolar-2018, o sistema público ofertava 39,5 milhões de matrículas (81,4\% do total das matrículas de educação básica) em 141,3 mil escolas com 1,86 milhão de docentes. Essa oferta é distribuída em quase 6.000 redes (26 estaduais, a rede distrital e 5.570 municipais). Em 2018, as redes estaduais foram responsáveis por 33\% das matrículas; as municipais, por $48 \%$; e a rede privada, por $19 \%$. Diante de uma rede pública com tais dimensões e da inexistência de um Sistema Nacional de Educação, é de se esperar que o Estado tenha grandes desafios quanto à coordenação e cooperação federativas para responder às consequências educacionais da pandemia.

Outro desafio marcante ao desempenho do sistema público de educação, além da extensão da cobertura, é a histórica desigualdade social no Brasil, expressa, segundo Cury (2008), na vitimização dos pobres, negros, indígenas, migrantes, moradores das periferias e das áreas rurais e pessoas com mais idade. A Tabela 1 mostra como a estratificação de oportunidades educacionais associada ao nível de renda da população, fenômeno recorrente nos países em desenvolvimento (Alves \& Silva, 2013; Barros, Mendonça, Santos, \& Quintaes, 2001; Buchmann \& Hannum, 2001), configura-se do ponto de vista do acesso e da conclusão do processo escolar. 


\begin{tabular}{lcc} 
Características & $\mathbf{5 0 \%}$ mais pobres ${ }^{1}$ & $\mathbf{1 0 \%}$ mais ricos $^{2}$ \\
\hline Taxa de escolarização - 0 a 3 anos & $29,0 \%{ }^{*}$ & $53,2 \%$ \\
Taxa de escolarização - 4 e 5 anos & $90,8 \%{ }^{*}$ & $98,3 \%$ \\
Taxa de escolarização - 6 a 14 anos & $99,2 \%{ }^{*}$ & $99,9 \%$ \\
Taxa de escolarização - 15 a 17 anos & $89,3 \%{ }^{*}$ & $99,4 \%$ \\
População de 4 a 17 anos que frequenta escola pública ${ }^{3}$ & $94,8 \%{ }^{*}$ & $10,4 \%$ \\
Taxa de analfabetismo - 15 anos ou mais & $9,3 \%{ }^{*}$ & $0,4 \%$ \\
População de 25 a 65 que completou o ensino médio & $34,8 \%{ }^{*}$ & $90,5 \%$ \\
População de 25 a 65 que completou curso de graduação & $4,2 \%{ }^{*}$ & $64,1 \%$
\end{tabular}

\section{Notas:}

(1) Em 2018, os 50\% mais pobres tinham renda per capita domiciliar de até R \$ 788 (0,83 do salário mínimo).

(2) Em 2018, os 10\% mais ricos tinham renda per capita domiciliar de R 2.600 (2,7 salários mínimos) ou mais.

(3) Valores referentes à população dos municípios das capitais dos estados brasileiros.

$\left({ }^{*}\right)$ Os resultados do teste qui-quadrado indicaram diferenças significantes entre os níveis de renda $(\mathrm{p}<0,001)$.

Fonte: Elaborada pelos autores com base nos microdados da Pesquisa Nacional por Amostra de Domicílios (Pnad) Contínua do $2^{\circ}$ trimestre/2018.

Os dados da Tabela 1 ressaltam o relevante papel da escola pública na garantia do direito à educação para a população mais pobre. Eles mostram, também, considerando o nível de renda, a diferença de acesso à educação infantil, etapa que gera significativo impacto na trajetória escolar das crianças (Bakken, Brown, \& Downing, 2017; Phillips et al., 2017) e, de algum modo, reflete-se na distância entre os $10 \%$ mais ricos e os $50 \%$ mais pobres na taxa de analfabetismo (diferença igual a 23 vezes) e na conclusão do ensino médio ( 2,4 vezes) e do ensino superior (17 vezes).

Quanto às responsabilidades dos entes federativos, as normas nacionais atribuem aos municípios prioridade no ensino fundamental e na educação infantil, e aos estados, nos ensinos fundamental e médio. A União deve organizar e manter a rede pública federal e prestar assistência financeira e técnica aos governos subnacionais, para equalizar oportunidades e garantir padrão mínimo de qualidade do ensino (CF [Art. 211], 1988).

No âmbito do financiamento, a Constituição Federal (CF, 1988) preceitua a aplicação de um percentual mínimo da receita líquida de impostos dos governos em manutenção e desenvolvimento do ensino - $18 \%$ para o governo federal e $25 \%$ para os entes subnacionais. Esta é a principal fonte para a educação, seguida por salário-educação, contribuição social recolhida por empresas e calculada sobre o total de remunerações dos empregados segurados, destinada ao financiamento da educação básica pública, com parcelas repartidas entre os entes da federação.

Quanto à divisão do gasto, em 2015, de um total de R \$321,3 bilhões de despesas públicas realizadas com recursos fiscais, os municípios foram responsáveis por 38,2\%, seguidos dos estados e Distrito Federal, com 32,5\%, e da União, com apenas 29,3\% (Inep, 2018). O esforço maior é realizado pelos governos subnacionais, com atuação direta na provisão de educação básica e apropriação relativamente menor do bolo tributário.

A cooperação federativa no financiamento é efetivada por meio de políticas de transferências intergovernamentais de recursos, sendo a principal o Fundo de Manutenção e Desenvolvimento da Educação Básica e de Valorização dos Profissionais da Educação (Fundeb), vigente desde 2007, com prazo de extinção ao final de 2020. O Fundeb possibilitou maior equiparação na capacidade de gasto dos entes da federação, mas, em virtude do pequeno valor do complemento federal, persistem grandes diferenças e o valor por aluno é muito baixo (Pinto, 2018). 


\section{ASPECTOS METODOLÓGICOS}

A análise do impacto da queda da arrecadação devido aos efeitos econômicos da crise sanitária no orçamento da educação básica de estados e municípios foi realizada tomando-se um modelo que permitiu construir cenários de estimativas de receitas de impostos vinculadas à educação básica. Esse modelo baseou-se nos seguintes quatro elementos:

(1) banco de dados contendo características da oferta educacional; as fontes de receitas de estados e municípios; coeficientes de distribuição de recursos do Fundeb; valores da complementação da União ao Fundeb;

(2) percentual de redução na arrecadação de ICMS e Imposto sobre Serviços (ISS) e das receitas do Fundo de Participação dos Estados (FPE), Fundo de Participação dos Municípios (FPM), ICMS-Desoneração e Cota-parte do ICMS;

(3) cálculo da 'receita potencial mínima vinculada para educação básical' (RPEb) para cada estado e município por meio da seguinte fórmula:

$$
R P E B=(25 \% \times R L I)-(R D F)+(R R F)+(C O U N)
$$

Onde:

${ }^{*} R P E B=$ Receita potencial mínima vinculada para educação básica

${ }^{*} R L I=\quad$ Receita líquida de Impostos ${ }^{1}$

${ }^{*} R D F=$ Receita destinada ao Fundeb estadual ${ }^{2}$

${ }^{*} R R F=$ Receita recebida do Fundeb estadual ${ }^{3}$

${ }^{*}$ COUN $=$ Complementação da União ao Fundeb ${ }^{4}$

\section{Notas:}

(1) Receita de impostos estaduais - ICMS (deduzido de 25\% para compor a cota-parte ICMS), Imposto sobre Transmissão Causa mortis e Doação (ITCD), Imposto sobre Propriedade de Veículos Automotores-IPVA (deduzido de 50\% para compor a cota-parte IPVA); impostos municipais - ISS, Imposto Territorial, Predial e Urbano (IPTU), Imposto sobre a Transmissão de Bens Imóveis (ITBI), Imposto Territorial Rural (ITR); receitas de transferências aos estados (cota-parte FPE); receitas de transferências aos municípios (cota-parte FPM, Cota-parte ICMS, cota-parte IPVA, cota-parte ITR) e transferências a estados e municípios - ICMS Desoneração, cota-parte Imposto sobre Operações Financeiras (IOF) Ouro e cota-parte Imposto sobre Produto Industrializado (IPI) Exportação (deduzida de 25\%); além da receita do Imposto sobre a renda retido na fonte (IRRF) por órgãos estaduais e municipais.

(2) Em cada estado, o Fundeb é composto por $20 \%$ da receita líquida de ICMS, IPVA, ITCD, cota-parte FPE, cota-parte ICMS, cota-parte IPVA, cota-parte FPM (alínea b), cota-parte ITR, ICMS Desoneração, cota-parte IPI Exportação.

(3) A receita total de cada fundo estadual é redistribuída internamente entre os entes federativos dos respectivos estados baseada no número de matrículas do ano anterior com ponderações (Art. 9º Lei n 11.494/2007).

(4) A União deve complementar com, no mínimo, 10\% do total dos recursos destinados por estados e municípios os fundos com menor valor por aluno por unidade federada.

Fonte: Elaborada pelos autores.

\footnotetext{
${ }^{1}$ A expressão "receita potencial mínima" é decorrente do disposto pelo Art. 212 da CF (1988), que estabelece um percentual mínimo da receita resultante de impostos e transferências. Desse modo, o indicador proposto é uma medida conservadora, uma vez que os entes federativos podem aplicar um valor além do mínimo.
} 
(4) Cálculo do indicador 'receita-aluno-mês' para facilitar a comparação dos resultados entre entes federativos, conforme a seguinte fórmula:

$$
\text { Receita_aluno_mês }=(R P E B) /\left(n \_m a t r\right) / 12
$$

Onde:

${ }^{\star} R P E B=$ Receita potencial mínima vinculada para educação básica (valor anual)

${ }^{\star}$ n_matr $=$ Número de matrículas da rede própria (estadual ou municipal) + ofertadas em instituições conveniadas

Fonte: Elaborada pelos autores.

O banco de dados do estudo foi construído com dados de 2018 (ano base de comparação das receitas). A entidade federativa (estados e municípios) foi a unidade de análise. O banco foi composto por 5.596 observações (26 estados, Distrito Federal e 5.570 municípios). Não foram obtidos dados de receitas de 38 municípios. Desse modo, obteve-se cobertura de 5.558 ou 99,3\% dos entes federativos responsáveis pela oferta de $99,7 \%$ das matrículas das redes públicas estaduais e municipais - ver variáveis e fontes dos dados no Quadro 1.

\section{QUADRO 1 VARIÁVEIS E FONTES DE DADOS}

\begin{tabular}{|c|c|c|}
\hline Aspecto & Variáveis & Fonte \\
\hline Receita pública & $\begin{array}{l}\text { ICMS, ITCD, IPVA, Cota-Parte FPE, IPTU, ITBI, ISS, IRRF, } \\
\text { FPM, Cota-Parte ICMS, ICMS Desoneração, Cota-Parte IPI, } \\
\text { Exportação, Cota-Parte IPVA, ITR, Cota- Parte ITR, Cota-Parte, } \\
\text { IOF Ouro }\end{array}$ & $\begin{array}{l}\text { Dados analíticos do Siope/FNDE; } \\
\text { RREO/Siconfi/STN; plataforma de } \\
\text { Transferências Constitucionais/STN }\end{array}$ \\
\hline $\begin{array}{l}\text { Financiamento da } \\
\text { educação }\end{array}$ & $\begin{array}{l}\text { Coef_distribuição_recursos_Fundeb, } \\
\text { Coef_distribuição_complementação_União }\end{array}$ & (2018) \\
\hline Contexto & número de matrículas & $\begin{array}{l}\text { Microdados do Censo Escolar/Inep } \\
\text { (2018) }\end{array}$ \\
\hline
\end{tabular}

Fonte: Elaborado pelos autores.

Relativamente ao segundo elemento, a proposta foi construir um modelo de análise do impacto da queda na arrecadação do financiamento para a educação e, não, fazer previsões com alto grau de precisão. Assim, foram considerados três cenários. No primeiro, o mais otimista, redução anual na arrecadação de ICMS, Cota-Parte ICMS, ICMS-Desoneração e ISS de 10\% e queda nas transferências no FPE e FPM de $5 \%^{2}$. No Cenário II, queda anual de $20 \%$ e $10 \%$ nos dois grupos de receita considerados, respectivamente. No Cenário III, pessimista, queda de 30\% e 15\% respectivamente.

\footnotetext{
${ }^{2}$ A Medida Provisória n. 938/2020 estabeleceu apoio financeiro aos estados e municípios por meio do FPE e FPM, para manter, de março a junho, o nível de recursos do mesmo período de 2019. Dado o curto período ora estabelecido para este auxílio, bem como o limite de seus valores, foram atribuídas reduções aos dois fundos (MP, 2020).
} 
O terceiro e quarto elementos do modelo consistem no cálculo dos indicadores de resultados. Nessas etapas, foram calculados RPEb e 'receita-aluno-mês' para cada estado e município que compôs a amostra dos 5.558 entes federativos analisados, considerando o percentual de redução da arrecadação nas fontes especificadas em cada cenário. Para estimar a redução das receitas, os resultados de cada ente federativo nos três cenários foram comparados ao valor realizado no ano base (2018). Os cálculos, por serem numerosos (três cenários x 5.558 entes federativos), foram realizados por meio de um programa computacional desenvolvido em software estatístico.

Os resultados apresentados na próxima seção foram gerados com base na agregação (somatório) dos resultados de cada ente federativo para diferentes níveis de análise: a Tabela 2 apresenta o impacto de cada cenário no agregado nacional; e a Tabela 3 apresenta resultados agregados por estado. Em outra perspectiva de análise, a Tabela 4 focaliza a variação de 'receita-aluno-mês' em cada cenário.

\section{CENÁRIOS DE REDUÇÃO DA ARRECADAÇÃO E IMPLICAÇõES PARA A EDUCAÇÃO BÁSICA}

A Tabela 2 apresenta dados da arrecadação e das receitas vinculadas para a educação básica em 2018. Da RLI de R $\$ 900,3$ bilhões de 2018, 52,4\% são compostos pelo ICMS (incluindo a cota parte transferida aos municípios e o ICMS desoneração). FPE e FPM correspondem a 21,2\% e o ISS a 7,2\%. As demais fontes compõem menos de um quinto da receita. Os recursos destinados ao financiamento da educação ( $\mathrm{R}$ \$ 238,9 bilhões) foram originados da vinculação de $25 \%$ dessas receitas de estados e municípios (R $\$ 225,1$ bilhões [94,2\% do total]) e da complementação da União ao Fundeb (R 13,8 bilhões [ $5,8 \%$ do total] $)^{3}$. As redes estaduais de ensino, em conjunto, ficaram com $56,4 \%$ dos recursos ( $\mathrm{R} \$ 134,8$ bilhões) e as redes municipais com $43,6 \%$ ( $\mathrm{R} \$ 104,1$ bilhões). No agregado nacional, essas fontes de financiamento garantiram uma receita por aluno mensal de $\mathrm{R} \$ 492,00$ para 40,5 milhões de matrículas.

No primeiro cenário, verifica-se redução das receitas vinculadas à educação da ordem de 7\%, ou seja, uma perda de $\mathrm{R} \$ 16,6$ bilhões, sendo $\mathrm{R}$ \$10,3 bilhões entre as redes estaduais e $\mathrm{R} \$ 6,3$ bilhões entre as redes municipais. A receita por aluno cairia para $\mathrm{R} \$ 458,00$ por mês. O segundo cenário resultou em decréscimo de 14\% na RLI, perda de R \$33,5 bilhões nos orçamentos da educação e queda de receita-aluno mês para $\mathrm{R} \$ 423,00$. Por fim, no cenário mais pessimista, haveria uma queda na RLI de $21,1 \%$, o que impactaria negativamente os recursos para educação em $\mathrm{R} \$ 50,4$ bilhões, resultando numa receita-aluno mês de apenas $\mathrm{R} \$ 388,00$.

Os dados da Tabela 3 mostram um panorama da diversidade da oferta educacional por Unidade da Federação (UF) em número de redes públicas e de matrículas. Ressalta também a desigualdade da capacidade de financiamento expressa pela mediana de receita-aluno-mês. Nesse sentido, a distância entre o menor valor ( $\mathrm{R} \$ 323,00$, relativo ao Maranhão) e o maior ( $\mathrm{R} \$ 460,00$, relativo ao Rio Grande do Sul) é de $90 \%$. Os números mostram uma expressiva desigualdade intra e inter-regional. Uma análise desagregada por ente federativo mostra que receita-aluno-mês de $\mathrm{R} \$ 460,00$ (média de 2018) poderá cair de $4,1 \%$ a $26,9 \%$, a depender do cenário de redução e contexto de cada município.

\footnotetext{
${ }^{3}$ Em virtude do escopo deste estudo e da ausência de dados por ente federado, o salário-educação não foi considerado. De todo modo, sua arrecadação bruta em 2018 foi de $\mathrm{R} \$ 22,1$ bilhões.
} 


\section{TABELA 2 RECEITA VINCULADA PARA O FINANCIAMENTO DA EDUCAÇÃO BÁSICA E CENÁRIOS DE REDUÇÃO DA ARRECADAÇÃO - BRASIL/2018 (EM BILHÕES DE R\$)}

\begin{tabular}{|c|c|c|c|c|c|}
\hline \multirow{2}{*}{ Fonte de receita } & \multicolumn{2}{|l|}{ Receita 2018} & \multirow{2}{*}{$\begin{array}{c}\text { Cenário I } \\
\text { R\$ }\end{array}$} & \multirow{2}{*}{$\begin{array}{c}\text { Cenário II } \\
\text { R\$ }\end{array}$} & \multirow{2}{*}{$\begin{array}{c}\text { Cenário III } \\
\text { R\$ }\end{array}$} \\
\hline & $\mathrm{R} \$$ & $\%$ & & & \\
\hline ICMS & 355,7 & 39,5 & 320,1 & 284,5 & 249,0 \\
\hline Cota-Parte ICMS & 114,0 & 12,7 & 102,6 & 91,2 & 79,8 \\
\hline FPM & 101,3 & 11,3 & 96,3 & 91,2 & 86,1 \\
\hline FPE & 89,4 & 9,9 & 85,0 & 80,5 & 76,0 \\
\hline ISS & 65,1 & 7,2 & 58,6 & 52,1 & 45,6 \\
\hline ICMS-Desoneração & 1,9 & 0,2 & 1,7 & 1,5 & 1,3 \\
\hline Demais fontes & 172,9 & 19,2 & 172,9 & 172,9 & 172,9 \\
\hline Receita Líquida de Impostos (RLI) & 900,3 & 100,0 & 837,1 & 773,9 & 710,7 \\
\hline Estimativa de redução da RCL & & & $-7,0 \%$ & $-14,0 \%$ & $-21,1 \%$ \\
\hline Financiamento da Educação Básica & & & & & \\
\hline 25\% da Receita Corrente Líquida & 225,1 & 94,2 & 209,3 & 193,5 & 177,7 \\
\hline Complementação da União ao Fundeb & 13,8 & 5,8 & 13,0 & 11,9 & 10,8 \\
\hline Receita potencial mínima vinculada (RPEb) & 238,9 & 100,0 & 222,3 & 205,4 & 188,5 \\
\hline Redução dos recursos destinados à educação & & & $-16,6$ & $-33,5$ & $-50,4$ \\
\hline Recursos para redes estaduais & 134,8 & 56,4 & 124,5 & 114,1 & 103,7 \\
\hline Estimativa de redução: & & & $-10,3$ & $-20,7$ & $-31,1$ \\
\hline Recursos para redes municipais & 104,1 & 43,6 & 97,83 & 91,32 & 84,80 \\
\hline Estimativa de redução: & & & $-6,3$ & $-12,8$ & $-19,3$ \\
\hline Número de matrículas & 40.472 .466 & & 40.472 .466 & 40.472 .466 & 40.472 .466 \\
\hline Receita-aluno por mês (em R\$1,00) & 492 & & 458 & 423 & 388 \\
\hline
\end{tabular}

Fonte: Elaborada pelos autores com base nos dados do Sistema de Informações sobre Orçamentos Públicos em Educação (Siope)/Fundo Nacional de Desenvolvimento da Educação (FNDE), do Relatório Resumido da Execução Orçamentária (RREO)/Sistema de Informações Contábeis e Fiscais do Setor Público Brasileiro (Siconfi)/Secretaria do Tesouro Nacional (STN), dados do portal 'Transferências Constitucionais'/STN e em microdados do Censo Escolar/Inep (2018). 


\section{TABELA 3 RECEITA VINCULADA E ESTIMATIVA DE REDUÇÃO DE RECURSOS PARA FINANCIAMENTO DA EDUCAÇÃO BÁSICA POR REGIÃO E UF-BRASIL/2018}

\begin{tabular}{|c|c|c|c|c|c|c|c|c|}
\hline \multirow{3}{*}{ Região } & \multirow{3}{*}{ UF } & \multirow{3}{*}{$\begin{array}{l}\text { Número } \\
\text { de redes } \\
\text { públicas1 }\end{array}$} & \multirow{3}{*}{$\begin{array}{l}\text { Número de } \\
\text { matrículas2 }\end{array}$} & \multicolumn{2}{|c|}{ Receita realizada 2018} & \multicolumn{3}{|c|}{ Perdas estimadas } \\
\hline & & & & $\begin{array}{c}\text { Receita } \\
\text { vinculada3 }\end{array}$ & $\begin{array}{l}\text { Receita- } \\
\text { aluno por } \\
\text { mês4 }\end{array}$ & Cenário I & Cenário II & Cenário III \\
\hline & & & & $\begin{array}{r}\mathrm{RS} \\
\text { (bilhões) }\end{array}$ & $\mathrm{R} \$(1,00)$ & R\$ (bilhões) & R\$ (bilhões) & R\$ (bilhões) \\
\hline \multirow{8}{*}{ Norte } & $A C$ & 23 & 268.949 & 1,41 & 360 & 0,08 & 0,17 & 0,25 \\
\hline & AM & 63 & 1.071 .569 & 5,15 & 341 & 0,37 & 0,77 & 1,17 \\
\hline & AP & 17 & 204.973 & 1,22 & 402 & 0,07 & 0,13 & 0,20 \\
\hline & PA & 138 & 2.043 .932 & 9,18 & 329 & 0,59 & 1,26 & 1,94 \\
\hline & R0 & 53 & 393.463 & 2,11 & 415 & 0,14 & 0,29 & 0,43 \\
\hline & $\mathrm{RR}$ & 16 & 141.056 & 0,94 & 456 & 0,06 & 0,11 & 0,17 \\
\hline & TO & 139 & 356.894 & 2,37 & 472 & 0,14 & 0,29 & 0,43 \\
\hline & Região & 449 & 4.480 .836 & 22,39 & 382 & 1,45 & 3,02 & 4,58 \\
\hline \multirow{10}{*}{ Nordeste } & $A L$ & 97 & 689.273 & 3,36 & 343 & 0,21 & 0,44 & 0,66 \\
\hline & $B A$ & 417 & 3.054 .741 & 15,02 & 353 & 1,00 & 2,07 & 3,15 \\
\hline & CE & 185 & 1.786 .525 & 8,57 & 341 & 0,56 & 1,15 & 1,74 \\
\hline & MA & 214 & 1.831 .674 & 8,00 & 323 & 0,49 & 1,05 & 1,61 \\
\hline & PB & 224 & 806.985 & 3,86 & 351 & 0,25 & 0,51 & 0,77 \\
\hline & $P E$ & 185 & 1.730 .761 & 8,87 & 351 & 0,61 & 1,23 & 1,86 \\
\hline & PI & 222 & 857.513 & 3,84 & 358 & 0,24 & 0,50 & 0,76 \\
\hline & RN & 166 & 646.302 & 3,43 & 378 & 0,23 & 0,47 & 0,70 \\
\hline & SE & 76 & 421.827 & 2,54 & 415 & 0,16 & 0,32 & 0,49 \\
\hline & Região & 1.786 & 11.825 .601 & 57,51 & 351 & 3,76 & 7,75 & 11,75 \\
\hline \multirow{5}{*}{ Sudeste } & ES & 78 & 766.169 & 4,30 & 399 & 0,33 & 0,65 & 0,98 \\
\hline & $M G$ & 851 & 4.025 .033 & 21,78 & 430 & 1,52 & 3,04 & 4,56 \\
\hline & RJ & 92 & 2.472 .561 & 16,76 & 432 & 1,21 & 2,42 & 3,63 \\
\hline & SP & 643 & 8.137 .989 & 60,49 & 532 & 4,36 & 8,71 & 13,07 \\
\hline & Região & 1.664 & 15.401 .752 & 103,33 & 464 & 7,41 & 14,82 & 22,23 \\
\hline \multirow{4}{*}{ Sul } & PR & 397 & 2.224 .909 & 13,75 & 478 & 0,95 & 1,89 & 2,84 \\
\hline & RS & 498 & 1.981 .857 & 13,57 & 610 & 1,03 & 2,06 & 3,09 \\
\hline & SC & 296 & 1.341 .655 & 8,86 & 531 & 0,65 & 1,30 & 1,94 \\
\hline & Região & 1.191 & 5.548 .421 & 36,18 & 541 & 2,62 & 5,25 & 7,87 \\
\hline
\end{tabular}




\begin{tabular}{|c|c|c|c|c|c|c|c|c|}
\hline \multirow{5}{*}{ Centro-Oeste } & DF & 1 & 476.115 & 3,37 & 589 & 0,20 & 0,40 & 0,60 \\
\hline & GO & 246 & 1.234 .143 & 7,22 & 482 & 0,50 & 1,00 & 1,50 \\
\hline & MS & 80 & 613.167 & 3,83 & 481 & 0,27 & 0,53 & 0,80 \\
\hline & MT & 141 & 784.306 & 4,67 & 491 & 0,33 & 0,66 & 0,99 \\
\hline & Região & 468 & 3.107 .731 & 19,09 & 484 & 1,30 & 2,60 & 3,90 \\
\hline BRASIL & & 5.558 & 40.364 .341 & 238,50 & 435 & 16,54 & 33,43 & 50,33 \\
\hline
\end{tabular}

\section{Notas:}

(1) Entes federados da amostra do estudo. Em cada UF há uma rede estadual e as redes municipais de ensino.

(2) Número de matrículas das redes municipais, estaduais e instituições conveniadas.

(3) $\mathrm{RPEd}=(25 \% \mathrm{x}$ RLI de cada UF $)+$ (Complementação da União do Fundeb, caso haja).

(4) Mediana de receita-aluno-mês em cada UF.

Fonte: Elaborada pelos autores com base nos dados analíticos do Siope/FNDE, do RREO/Siconfi/STN, dados do portal 'Transferências Constitucionais'/STN e em microdados do Censo Escolar/INEP (2018).

A Tabela 3 fornece detalhadamente, por UF e região, os valores necessários para recomposição dos orçamentos da educação básica se forem confirmados os cenários de redução na arrecadação de impostos. No cenário I, por exemplo, que demandaria R $\$ 16,5$ bilhões nacionalmente, deveriam ser destinados R \$ 1,45 bilhão para os estados do Norte (8,8\%), R \$ 3,76 bilhões para o Nordeste (22,7\%), R \$ 7,41 bilhões para o Sudeste (44,8\%), R \$ 2,62 bilhões para os estados do Sul (15,9\%) e R\$ 1,3 bilhão para o Centro-Oeste (7,9\%). Alguns estudos (Alves e Silva, 2013; Inep, 2018) evidenciam que os estados das regiões Norte e Nordeste enfrentam, em geral, maiores desafios educacionais em virtude doo acesso, das condições de oferta e dos resultados. O foco, aqui, contudo, é a recomposição de valores dos orçamentos no contexto da pandemia da COVID-19, uma vez que cada rede pública do país tem compromissos orçamentários historicamente assumidos para manutenção de suas escolas.

Esses números evidenciam uma das principais limitações do sistema de financiamento da educação básica vigente: a capacidade de financiamento das redes públicas associada à capacidade de arrecadação, dada a riqueza local. Portanto, o sistema não tem um importante atributo: neutralidade de riqueza ou neutralidade fiscal (Berne \& Stiefel, 1984). Sendo assim, as condições para a garantia do direito à educação ficam suscetíveis à capacidade fiscal da localidade onde as crianças, os jovens e os adultos moram.

A Tabela 4 mostra que, em 2018, o sistema de financiamento da educação básica gerou receitaaluno-mês de R\$ 460,00, em média, para as 5.558 redes públicas analisadas, todavia, com uma desigualdade expressiva $(\mathrm{CV}=29,6 \%)$. 


\section{TABELA 4 ANÁLISE DA VARIAÇÃO DE RECEITA-ALUNO-MÊS ENTRE REDES PÚBLICAS ${ }^{1}$ E CENÁRIOS DE REDUÇÃO - BRASIL/2018}

\begin{tabular}{|c|c|c|c|c|c|c|c|c|}
\hline \multirow{3}{*}{\multicolumn{2}{|c|}{ Medidas descritivas }} & \multirow{2}{*}{$\begin{array}{l}\text { Receita-aluno } \\
\text { por mês } 2018^{2}\end{array}$} & \multicolumn{2}{|c|}{ Cenário I } & \multicolumn{2}{|c|}{ Cenário II } & \multicolumn{2}{|c|}{ Cenário III } \\
\hline & & & $\begin{array}{l}\text { Receita- } \\
\text { aluno-mês }\end{array}$ & redução & $\begin{array}{l}\text { Receita- } \\
\text { aluno-mês }\end{array}$ & redução & $\begin{array}{l}\text { Receita- } \\
\text { aluno-mês }\end{array}$ & redução \\
\hline & & $\mathrm{R} \$(1,00)$ & $\mathrm{R} \$(1,00)$ & $\%$ & $\mathrm{R} \$(1,00)$ & $\%$ & $\mathrm{R} \$(1,00)$ & $\%$ \\
\hline \multicolumn{2}{|l|}{ Média } & 460 & 428 & $-7,0 \%$ & 395 & $-14,1 \%$ & 362 & $-21,3 \%$ \\
\hline \multicolumn{2}{|c|}{ Desvio-padrão } & 136 & 127 & $0,5 \%$ & 118 & $0,9 \%$ & 109 & $1,3 \%$ \\
\hline \multicolumn{2}{|c|}{ Coeficiente de variação } & $29,6 \%$ & $29,6 \%$ & & $29,8 \%$ & & $30,1 \%$ & \\
\hline \multicolumn{2}{|l|}{ Menor } & 224 & 209 & $-9,0 \%$ & 194 & $-18,0 \%$ & 179 & $-26,9 \%$ \\
\hline \multirow[t]{5}{*}{ Percentiles } & $1 \%$ menor & 288 & 269 & $-8,1 \%$ & 248 & $-16,1 \%$ & 228 & $-24,2 \%$ \\
\hline & 10 quartil & 362 & 337 & $-7,3 \%$ & 311 & $-14,6 \%$ & 285 & $-22,0 \%$ \\
\hline & mediana & 435 & 404 & $-7,0 \%$ & 373 & $-14,2 \%$ & 342 & $-21,4 \%$ \\
\hline & 30 quartil & 518 & 481 & $-6,6 \%$ & 444 & $-13,5 \%$ & 407 & $-20,5 \%$ \\
\hline & $1 \%$ maior & 929 & 865 & $-5,9 \%$ & 801 & $-11,9 \%$ & 738 & $-17,9 \%$ \\
\hline \multicolumn{2}{|l|}{ Maior } & 2.451 & 2.314 & $-4,1 \%$ & 2.176 & $-8,3 \%$ & 2.038 & $-12,4 \%$ \\
\hline \multicolumn{2}{|c|}{ Amplitude: máximo/mínimo } & 10,95 & 11,06 & & 11,20 & & 11,37 & \\
\hline \multicolumn{2}{|c|}{ Amplitude: $1 \%$ maior $/ 1 \%$ menor } & 3,23 & 3,21 & & 3,22 & & 3,24 & \\
\hline
\end{tabular}

\section{Notas:}

(1) Foram analisados os dados das redes públicas de 26 estados, do Distrito Federal e de 5.531 municípios.

(2) $\mathrm{RPEb} \div$ número de matrículas $\div 12$.

Fonte: Elaborada pelos autores com base em dados analíticos do Siope/FNDE, dados do RREO, disponibilizados pelo Siconfi/STN, dados da plataforma de Transferências Constitucionais/STN e em microdados do Censo Escolar/Inep. Todas as fontes são referentes a 2018.

Para uma noção das especificidades e do nível de desigualdade dos contextos educacionais brasileiros, de acordo com os números da Tabela 4, em 2018 a diferença entre o menor valor de receitaaluno-mês ( $\mathrm{R} \$ 244,00$ em Monte Horebe- $\left.\mathrm{PB}^{4}\right)$ e o maior valor $\left(\mathrm{R} \$ 2.451,00\right.$ em Douradoquara- $\mathrm{MG}^{5}$ ) chegava a quase 11 vezes. Mesmo se retirados os valores extremos (1\% menor e 1\% maior), a diferença permanece considerável (3,23 vezes). Os dados dos cenários de estimativa de redução da arrecadação no contexto da pandemia da COVID-19 mostram que os valores da receita por aluno, atualmente já muito baixos se comparados aos valores de mensalidades de escolas privadas da classe média, poderão cair significativamente: de $4,1 \%$ a $26,9 \%$, a depender do cenário. No cenário I, a redução pode variar de $4,1 \%$ a $9,0 \%$. A variação seria de $8,3 \%$ a $18 \%$ no cenário II e de $12,4 \%$ a $26,9 \%$ no cenário III.

\footnotetext{
${ }^{4}$ Monte Horebe-PB tinha 4.793 habitantes em 2016. Em 2018, ofertava 1.374 matrículas na rede municipal e era responsável por 82\% do total das matrículas de educação básica do município.

${ }^{5}$ Douradoquara-MG tinha cerca de 2 mil habitantes em 2016 e apenas 31 alunos na rede municipal. Era responsável por apenas 9,7\% das matrículas da educação básica da localidade.
} 


\section{CONSIDERAÇÕES FINAIS}

Com a imbricação das crises econômica e sanitária e com a suspensão das atividades letivas por longo período, é plausível prever demandas adicionais para a educação pública, as quais, junto com a continuidade dos serviços já oferecidos, pressionarão as redes para expansão da oferta, em contexto de redução das receitas vinculadas ao ensino.

Como enfrentar este desafio? Destaca-se, inicialmente, o papel constitucional da União de suplementar recursos, considerando sua responsabilidade de garantir equidade e padrão de qualidade na educação. Nesse marco, advoga-se pelo aumento imediato da complementação da União ao Fundeb. A aprovação da PEC 15/2015, com a implantação do novo Fundeb já em 2021, é outra medida viável em curto prazo. A previsão de aumento da complementação da União e as novas regras para a sua repartição vão beneficiar redes públicas com menor capacidade de gasto em todos os estados da federação.

Os programas mais tradicionais de assistência financeira da União aos estados e municípios na educação básica, que têm sofrido decréscimo nas aplicações nos anos mais recentes, precisam de uma expressiva injeção de recursos. De modo mais premente, pelo escopo da cobertura, o Programa Nacional de Alimentação Escolar (Pnae), o Programa Nacional de Apoio ao Transporte Escolar (Pnate) e o Programa Dinheiro Direto na Escola (PDDE).

Urge também a implantação de auxílio financeiro da União que compense a perda de receitas vinculadas em manutenção e desenvolvimento do ensino (MDE) ${ }^{6}$ em todo o país, pois a complementação ao Fundeb, mesmo que aumente em 2020, destina-se a fundos estaduais com valores mais baixos por aluno.

Duas medidas foram editadas recentemente para compensar perdas de receitas: a Medida Provisória $n^{\circ}$ 938/2020 (MP, 2020), que estabelece apoio financeiro aos estados e municípios, para manter, de março a junho de 2020, o nível de recursos do FPE e FPM transferidos no mesmo intervalo de 2019 (com o limite de até 16 bilhões de reais); e a Lei Complementar n 173/2020 (LC, 2020), que cria o Programa Federativo de Enfrentamento ao Coronavírus, na qual há previsão de repasse de 50 bilhões nos chamados "recursos livres" (não vinculados às ações das áreas da saúde e assistência social) aos governos estaduais e prefeituras. Em ambas, não foi estipulada a observância da vinculação de uma proporção a MDE.

Apesar da lacuna no âmbito legal, é razoável cogitar a ocorrência de ações administrativas e judiciais para destinação compulsória a MDE de uma parte dos auxílios emergenciais mencionados. De todo modo, frente às estimativas e aferições de decréscimos acentuados nas receitas de impostos, providências para proteger a receita da educação são imprescindíveis em curto prazo. Nessa perspectiva, o Projeto de Lei ${ }^{\circ} 3.165$, protocolado na Câmara dos Deputados no início de junho de 2020, preconiza transferência de R $\$ 31$ bilhões aos governos subnacionais para aplicação nas suas redes de educação básica, a serem distribuídos conforme o número de matrículas presenciais de cada ente em 2019. A estimativa que embasou este PL foi a perda de $12 \%$ nas receitas da educação, o que se aproxima do segundo cenário projetado (Tabela 2) no presente estudo. Em sua tramitação no Congresso Nacional, possivelmente serão disputados o montante e o critério de distribuição, temas para os quais este texto fornece subsídios iniciais.

\footnotetext{
${ }^{6}$ O Art. 70 da Lei no 9.394/1996 (Lei de Diretrizes e Bases da Educação Nacional) especifica como despesa em manutenção e desenvolvimento do ensino aquelas realizadas com vistas à consecução dos objetivos básicos das instituições educacionais.
} 
RAP | Implicações da pandemia da COVID-19 para o financiamento da educação básica

Finalmente, é importante ressaltar o papel virtuoso que o gasto educacional exerce na economia (Instituto de Pesquisa Econômica Aplicada [IPEA], 2011). Entre 80\% e 90\% das despesas educacionais são destinadas ao pagamento de professores e funcionários de escolas (aproximadamente quatro milhões de trabalhadores). Pelo perfil de remuneração destes profissionais, boa parte dos salários transforma-se em consumo, com efeitos imediatos na atividade econômica e na arrecadação de tributos pelos 5.570 municípios onde eles vivem. Portanto o investimento educacional possui uma enorme capilaridade, atingindo de forma orgânica todos os poros econômicos da nação. 


\section{REFERÊNCIAS}

Alves, T., \& Silva, R. M. (2013). Estratificação das oportunidades educacionais no Brasil: contextos e desafios para a oferta de ensino em condições de qualidade para todos. Educação \& Sociedade, 34(124), 851-879.

Baker, B. D., \& Di Carlo, M. (2020). The coronavirus pandemic and K-12 Education Funding. Washington, DC: Albert Shanker Institute. Recuperado de https:// www.shankerinstitute.org/resource/coronaviruspandemic-and-k-12-education-funding

Bakken, L., Brown, N., \& Downing, B. (2017). Early childhood education: the long-term benefits. Journal of Research in Childhood Education, 31(2), 255-269.

Barros, R. P., Mendonça, R., Santos, D. D., \& Quintaes, G. (2001). Determinantes do desempenho educacional no Brasil (Texto para discusssão n. 834, pp. 1-33). Rio de Janeiro, RJ: IPEA.

Berne R., \& Stiefel. L. (1984). The measurement of equity in school finance: conceptual, methodological and empirical dimensions. London, UK: The John Hopkins University Press.

Buchmann, C., \& Hannum, E. (2001, agosto). Education and stratification in developing countries: a review of theories and research. Annual Review of Sociology, Palo Alto, 27, 77-102.

Constituição da República Federativa do Brasil, de 5 de outubro de 1988. (1988). Atualizada até a Emenda Constitucional no 106, de 07 de maio de 2020.

Cury, C. R. J. (2008). A educação escolar, a exclusão e seus destinatários. Educação em Revista, (48), 205-222. Recuperado de https://doi.org/10.1590/ S0102-46982008000200010

Instituto de Pesquisa Econômica Aplicada. (2011). Gastos com a Política Social: alavanca para o crescimento com distribuição de renda. (Comunidados do IPEA, n. 75). Brasília, DF: IPEA.

Instituto Nacional de Estudos e Pesquisas Educacionais Anísio Teixeira. (2018). Relatório do segundo ciclo de monitoramento das Metas do Plano Nacional de Educação - 2018. Brasília, DF: Inep.
Lei Complementar n. 173, de 27 de maio de 2020. (2020). Estabelece o Programa Federativo de Enfrentamento ao Coronavírus SARS-CoV-2 (Covid-19), altera a Lei Complementar no 101, de 4 de maio de 2000, e dá outras providências.

Lei n. 9.394, de 20 de dezembro de 1996. (1996). Estabelece as Diretrizes e Bases da Educação nacional, e dá outras providências.

Medida Provisória n. 938, de 02 de abril de 2020. (2020). Dispõe sobre a prestação de apoio financeiro pela União aos entes federativos que recebem recursos do Fundo de Participação dos Estados - FPE e do Fundo de Participação dos Municípios - FPM [...].

Organização para a Cooperação e Desenvolvimento Econômico (2019). Education at a Glance 2019. Paris, FR: OECD Publishing. Recuperado de https:// doi.org/10.1787/f8d7880d-en

Phillips, D. A, Lipsey, M. W., Dodge, K. A, Haskins, R., Bassok, D. ...Weiland, C. (2017). Puzzling it out: the current state of scientific knowledge on pre-k effects: a consensus statement. Washington, DC: The Brookings Institution.

Pinto, J. M. R. (2018). O financiamento da educação na Constituição Federal de 1988: 30 anos de mobilização social. Educação \& Sociedade, 39(145), 846-869.

Projeto de Lei n. 3.165, de 08 de junho de 2020. (2020). Dispõe sobre ações emergenciais destinadas à educação básica pública a serem adotadas durante o estado de calamidade pública reconhecido pelo Decreto Legislativo n. 6, de 20 de março de 2020, e dá outras providências.

Watanabe, M. (2020, 09 de abril). Estados já constatam forte queda na receita de ICMS. Valor Econômico. Recuperado de https://valor.globo.com/ impresso/noticia/2020/04/09/estados-ja-constatamforte-queda-na-receita-de-icms.ghtml

World Bank. (2020, April). The Economy in the Time of Covid-19. LAC Semiannual Report. Washington, DC: World Bank. Recuperado de https://openknowledge.worldbank.org/ handle/10986/33555 


\section{Thiago Alves}

https://orcid.org/0000-0002-5746-3386

Doutor em Administração pela Faculdade de Economia, Administração, Contabilidade e Atuária da Universidade de São Paulo (FEA/USP); Professor da Faculdade de Administração, Ciências Contábeis e Ciências Econômicas da Universidade Federal de Goiás (FACE/UFG) no Programa de Pós-Graduação em Administração (PPGADM/UFG) e no Programa de Pós-Graduação em Educação (PPGE) da Universidade Federal do Paraná (UFPR). E-mail: thiagoalves.edu@gmail.com

\section{Nalú Farenzena}

https://orcid.org/0000-0003-2582-5925

Doutora em Educação; Professora da Universidade Federal do Rio Grande do Sul no Programa de Pós-Graduação em Educação (FACED/UFRGS); Presidente da Associação Nacional de Pesquisa em Financiamento da Educação (FINEDUCA). E-mail: nalu.farenzena@gmail.com

\section{Adriana Aparecida Dragone Silveira}

https://orcid.org/0000-0001-6022-627X

Doutora em Educação; Professor da Universidade Federal do Paraná (UFPR) no Departamento de Planejamento e Gestão Escolar e Programa de Pós-Graduação em Educação. E-mail: adrianadragonesilveira@gmail.com

\section{José Marcelino de Rezende Pinto}

https://orcid.org/0000-0001-8355-2561

Doutor em Educação pela Universidade Estadual de Campinas (UNICAMP); Professor da Universidade de São Paulo (USP); Ex-presidente da Associação Nacional de Pesquisa em Financiamento da Educação (FINEDUCA). E-mail: jmrpinto@ffclrp.usp.br 